\title{
special feature to news from our chapters
}

Editor's note: This article was written to show how chapter activity can enhance science education in area schools. Any chapters willing to share their experiences in this realm are invited to contact the News Editor.

\section{Madison Chapter of the AMS Initiative to Enhance Weather Education in Area Schools}

\author{
Pamela Naber, ${ }^{*+}$ Edward Hopkins, ${ }^{*}$ \\ Alan Czarnetzki, ${ }^{*}$ Michael Alexander, ${ }^{\star}$ and \\ Terrie Fairgrieves*
}

\begin{abstract}
An initiative to enhance pre-college weather eduction was undertaken in 1990 by the Madison AMS chapter. A detailed survey was sent to selected science teachers in the Madison area to determine the needs of the schools. Based on the results of the survey, an education committee recommended a mix of items to be purchased for use by the teachers. Funding for the education initiative was provided through profits from the sale of a local weather calendar. The committee viewed and evaluated educational software, audiovisual materials and other items. The purchase of selected materials was approved by the AMS chapter. Purchased materials and additional information were distributed to educators in a workshop which allowed discussion and testing of software.
\end{abstract}

\section{Introduction}

The Madison Chapter of the American Meteorological Society was formed in 1987 at the University of Wisconsin-Madison with the goal of fostering interest in atmospheric and related sciences among students, faculty, and the local community. The chapter is primarily a student organization, although membership is open to anyone interested in the weather. Since 1988 , the chapter has produced a yearly local weather calendar in cooperation with WISC-TV, the local CBS affiliate. This calendar is sold in area retail stores, with all profits from the sales going to the local AMS chapter for use in carrying out its stated goals. The chapter has put a substantial portion of this income into local outreach programs.

The chapter determined that a good way to promote interest in weather and climate locally would be to enhance the study of meteorology in area primary and secondary schools. The chapter formed an Education Committee which met weekly to set goals for the project, to carry out necessary research, and to

\footnotetext{
*Madison Chapter of the American Meteorological Society Education Committee

+Corresponding author address: Madison AMS Chapter, 1225 W. Dayton St. Madison, WI 53076
}

prepare a tentative proposal on specific outreach activities for discussion and approval by the chapter.

The intent of this article is to describe how the Madison AMS chapter planned and carried out this outreach project. In so doing, we hope to encourage other local AMS chapters to undertake their own community projects by providing an example which proved successful. Some atmospheric science departments are also involved in this field (Smith et al. 1988). We also note that the national AMS organization has initiated a major effort to improve meteorological education (Houghton 1990) and will be undertaking work similar to that described here on a much grander scale in the future. Our efforts indicate that individual AMS chapters can enhance local meteorological education by working closely with area schools.

\section{Identification of needs}

To carry out the project successfully, the committee first needed to determine where and how weather and climate topics were taught, and which methods and materials teachers used to illustrate their lessons. These questions were answered by contacting local teachers, asking for input by means of a survey, and evaluating the results of this questionnaire.

\section{a. Developing contacts}

The committee looked for contacts in local schools through a variety of means. Names of high school earth science teachers in Madison were provided by the president of the Wisconsin Society of Science Teachers. Several school districts in surrounding areas were also contacted to inform them of our project and to solicit their help. In some cases, teachers were recommended by others and subsequently contacted. No attempt was made to be exhaustive due to constraints on the committee's time (most of the members are graduate students).

The committee also publicized the outreach program at the annual meeting of the Wisconsin Society of Science Teachers, held in April 1990. Three members of the Education Committee attended the meeting and staffed a table displaying calendars and information about the organization. Alan Czarnetzki also presented a short report on our activities. Many state science teachers both from Madison and from outside the Madison area were contacted at the gathering and provided feedback to the committee on the outreach project. Most of their comments are scheduled to be incorporated into chapter activities in 1991. 


\section{b. Educational survey}

Once earth science teachers were identified, they were asked to fill out a survey which the committee used to determine how its goals could best be met. ${ }^{1}$ In general, the survey was designed to measure the breadth of weather education in the schools and to determine which methods and materials are presently used. The survey also asked which materials would be of most use to the teachers in the future and asked for names of other potential contacts.

Completed surveys were received from five public high school earth science teachers; two districts in the Madison area also sent replies encompassing both primary and secondary science programs. While this is not a large sample size, it did provide the committee with valuable information on what actions would be most useful.

The first portion of the survey concentrated on determining which courses currently taught include components of weather and climate. The high school teachers indicated that each school offers at least one and sometimes two earth science courses. The main 2 -semester earth science course is populated by 10 thto 12th-graders who generally do not go on to college (according to their teachers). Typically each school offers two to three sections of approximately 25 students each. Meteorology usually accounts for $20 \%$ $30 \%$ of the subject matter.

Besides the main high school earth science course, meteorology is a part of several other elementary and middle school courses. It is usually integrated into a general science program, where weather and climate topics are covered as a unit within the course. At this level, varying interests and backgounds of the teachers in part determines the amount and distribution of time spent on weather and climate topics. The survey indicates that teachers cover a wide variety of subjects in the meteorology portions of the courses, and are mainly restricted in their choices by lack of time.

The second portion of the survey looked at classroom methods and materials. All teachers use a variety of techniques to teach weather and climate, including discussion of audio-visual (AV) materials. Videotapes and movies are used most often. The teachers also illustrate their lessons with thermometers, barometers, and other weather instruments. One high school additionally owns a weather station which records daily weather information. Teachers indicated that most of this material was owned by the school, although some also use items which were purchased with their own money.

In addition to AV materials and weather instruments, all of the responding schools own computers.

\footnotetext{
${ }^{1} A$ copy of this survey is available from the corresponding author.
}

The schools own primarily Apple $\| \circledast$ series computers, though several schools also have access to IBM-PCs® or Apple MACINTOSHes ${ }^{\circledR}$. Some teachers have computers available in their classrooms, while others have access to computer labs set up in other parts of the school building. Most teachers do not own or have access to any weather-specific software to use on these computers.

The last section of the survey asked teachers what additional materials would be most useful to them in teaching about the atmosphere. Videotapes were by far the most desired item, followed by software, slides, and filmstrips. In general, high school teachers preferred videotapes and software, while elementary teachers were more interested in filmstrips, books, and simple instruments. Most teachers also thought that access to an equipment library from which they could borrow bulky, expensive, or seldom used weather instruments might be useful for classroom demonstrations. In addition, the teachers expressed interest in having members of the local AMS chapter visit their classes to talk about weather-related topics. Overall, they preferred to have access to materials which would capture the students' attention and which would promote active learning experiences.

\section{Implementation}

\section{a. Proposal design}

After evaluating the surveys, the committee used seven general guidelines to assist in the design of the project. These guidelines questioned the number of schools which could be effectively serviced, the needs of the schools, the quality of available material, the educational opportunities versus chapter workload; the total cost, the diversity of materials to be donated, and the time available to organize the proposal.

The committee discussed a variety of directions the project might take. One option was donating a single expensive item, such as a weather station to one school. Another was donating many smaller, less costly items, such as software packages, to several schools. The committee also discussed the usefulness of various types of AV material.

The committee decided on a preliminary mix of one large item for a single school with a number of smaller materials going to other schools and teachers. An overview of the preliminary choices was prepared and presented for discussion at the February 1990 business meeting, including:

1) Was the chapter willing to maintain equipment over a long period of time, as would be required for a weather station?

2) Would donations of materials to schools be permanent or short-term in nature? 
3) How would the quality of the material be determined?

4) How would the material be distributed?

Based on the result of the discussion and the guidelines listed above, the committee decided to postpone the purchase of large, expensive equipment for at least one year. We felt that there was insufficient time to thoroughly study the quality of available systems. In addition, we were unsure of which teachers might have the enthusiasm and interest to most effectively use such equipment. Instead, we decided to buy a number of smaller items which would provide something to everyone involved. This widespread contact would also help to build connections between the AMS chapter and the educational community.

\section{b. Location and review of materials}

Once the basic structure of the proposal was formed, the committee set out to identify appropriate materials to donate to the teachers. Two committee members concentrated on locating well-designed audio-visual materials which teachers could either borrow from the chapter or which the chapter could give them outright. Two other committee members searched for and previewed available instructional software. A fifth member located sources of other educational material such as weather kits (a set of simple instruments to be used for demonstrations and student activities at the elementary school level).

The committee concluded that AV materials are variable in quality and accessability. Many commercially produced videotapes and movies are prohibitively expensive for purchase, although they are generally of high quality and reasonably current. Many inexpensive films available for rent or loan are dated and of limited use, especially since schools are moving towards increased use of videotapes rather than movies. (Madison School District schools are no longer allowed to purchase film projectors.) Footage of specific tornadoes and hurricanes produced by stormchasers is often spectacular and conveys excitement, but may have limited educational value.

The search for software was aided by access to two software libraries and resource centers located in the Madison area. Software packages were previewed at the University of Wisconsin (UW) School of Education Microcomputer Laboratory and at the Wisconsin Department of Public Instruction software library. These centers provided a variety of computers, programs, and personal expertise which helped us find and evaluate approximately ten software packages. Listings for other packages were found in The Educational Software Selector, a published guide which is available in many educational resource centers along with journals reviewing educational software. The available software was screened primarily for accuracy and ease of use rather than educational quality, since the evaluators had limited experience with using computers in a precollege classroom setting.

c. Selection of materials and approval by the chapter Once all easily available materials had been screened, the committee selected the materials to be purchased. ${ }^{2}$ Multiple copies of five software packages were chosen so that teachers could share information on classroom use and quality of material. Copies of a videotape of satellite images and an accompanying manual produced at the University of Wisconsin were also chosen to be given to all the participating schools. Five other audio-visual packages and six slide sets were selected by the local chapter to loan to teachers at no charge. Two weather kits were also chosen for local elementary schools. In addition, a resource list and meteorological glossary was prepared by Ed Hopkins, one of the committee members, to be provided to the teachers for their own use. A final proposal was written specifying the items to be purchased, their prices, and the costs of the workshop. This proposal was presented to the entire local Madison chapter for discussion and was unanimously approved.

\section{Distribution of materials}

The committee planned to provide these items in a teacher workshop which would allow interaction of earth science teachers with each other and with the chapter members. Twelve educators from primary and secondary schools attended our workshop, held 23 May 1990. To accomodate the participants' schedules, the workshop consisted of two software demonstration periods and a preview of the donated videotape. Teachers were asked to attend only one of the software sessions. An informal dinner was held between the first software session and the videotape viewing.

The participants were able to try several of the software packages on APPLE Ile ${ }^{\circledR}$ computers in each session. (Those who attempt similar software demonstrations might note that APPLE II computers can be very difficult to find in the university setting.) The teachers discussed how the software might be used in the classroom. They noted, however, that many of the available packages are written as tutorials and are not suitable for group use. They also said that they were especially interested in software which would allow the students to design their own experiments, which is rare in current software offerings. The sessions were

\footnotetext{
2 The committee has chosen not to name the specific products, since our choices were made on an experimental basis and were chosen from a small subset of available material.
} 
very informal and allowed teachers ample time to interact with each other and with the committee. Committee members who had previously tested the programs were available as software "experts."

During the software session, the teachers were also able to examine a variety of additional items. The Wisconsin State Climatologist's office provided surplus weather maps for the teachers to take with them for use in laboratory exercises, as well as pamphlets on winter storms, tornadoes, and career opportunities in meteorology. Books on simple weather experiments, folklore, and Wisconsin climate were also displayed for the teachers to examine.

The videotape discussion introduced teachers to the material presented on the tape and helped them to determine ways in which it might be used most effectively. Russ Schneider, a chapter member who had helped develop the original videotape, led the discussion and pointed out features of the satellite imagery on the tape to help the teachers interpret the images. Teachers were also shown computer-generated 4dimensional imagery developed and described by Hibbard et al. (1989) of the University of Wisconsin Space Science and Engineering Center. The teachers were impressed with the potential this graphical approach had to illustrate atmospheric principles, and encouraged development of audio-visual materials which would take advantage of these capabilities.

At the end of the night, teachers took their software, videotapes, and other items with them. They expressed their appreciation for both the donated materials and the chance to meet other earth science professionals in an informal setting. Chapter members also agreed that the experience had given them a broader appreciation for teaching science outside the university setting. Another workshop is being considered for next year.

\section{Conclusions}

Based on the results of the year's activities, the committee has many plans for continuing their work in the coming year. Members hope to continue previewing educational software and audio-visual materials for possible donation next year. The chapter is in the process of developing a "speaker bureau" which can provide members to talk on a variety of weather and climate topics. In addition, planning for next year's calendar is underway; we hope that this will provide us with additional funds for a weather station or other substantial purchase.

Our activities this past year have shown that enhanced local meteorological education at the elementary and secondary school levels is not beyond the reach of local AMS chapters. There are a number of ways in which students, professionals, and interested amateur meteorologists can become involved in outreach activities. Many teachers expressed the desire to have year-long "science consultants" to help them teach about different aspects of a particular subject. These consultants could visit schools on a regular basis to help set up weather stations and laboratories, and to talk to classes about severe weather, forecasting, climate change, and other topics of interest. Even chapter members with a limited amount of time to spend on outside interests could participate in this activity.

Chapters with more time and money could help organize teacher workshops or open houses to introduce local educators to their organizations and abilities. Donation of weather-related materials is appreciated by science teachers on a tight budget, but personal contact is even more useful, especially on an ongoing basis. Chapters could also try to improve their visibility by increasing participation in science fair judging and other educational activities.

We hope that we have been able to provide some insight into our attempts to tackle this problem, and we encourage other groups to develop their own methods for making meteorology more visible in their local communities. We would appreciate hearing of other resources and methods which we can use in future years.

Author's Note: Since this article was written, progress has continued, albeit at a reduced rate. Turnover of the committee members as students graduate or become more involved in research has required time to regroup and refocus our efforts. However, based on our experiences of last year, we have rewritten the survey to better identify current needs in weather education. We have also produced a second survey tailored to elementary curricula. This year we expanded our efforts by sending out 50 surveys to secondary schools from approximately ten different school districts in south-central Wisconsin. We have also developed contacts with the Madison Metropolitan School District to help us reach the numerous elementary schools most effectively. In addition to contacting new school systems, we also wrote to the teachers that participated last year to get feedback on the spring 1990 workshop. Teachers were generally pleased with the material they had been given, but commented that the software was not useful for classwork. We are using comments from these surveys to produce an updated reference guide to weather-related software, audio-visual materials, equipment, and other materials. We hope to make the guide available to science teachers this spring at the next workshop.

Acknowledgments. The Madison AMS Education Committee would 
like to acknowledge the help of the following individuals and organizations: David Houghton and Linda Keller of the national AMS Education Committee, for their information, interest, and encouragement; Mary Ann Fix of the Wisconsin Department of Public Instruction, for her help in identifying useful software; the University of Wisconsin (UW) Madison Departments of Meteorology and Geology and Geophysics, for their donation of space and equipment for the workshop; WISC-TV and the AMS Madison chapter, for their support of the calendar which funded this effort; Russ Schneider of UW-Madison, for his contributions to committee discussion and his participation in the workshop; and finally, the late Lyle Horn of the UW-Madison, for teaching us to value excellent education at all levels.

\section{References}

Hibbard, W., L. Uccellini, D. Santek and K. Brill, 1989: Applications of the 4-D McIDAS to a model diagnostic study of the President's Day cyclone. Bull. Amer. Meteor. Soc., 70, 1394-1403.

Houghton, D., 1990: American Meteorological Society education initiatives (editorial). Bull. Amer. Meteor. Soc., 71, 648.

Smith, D. R., G. H. Krockover, J. T. Snow, M. E. Akridge, S.B. Harley and T.M. McClelland, 1988: Atmospheric science education program at Purdue University: Summer program for teachers (grades 5-9). Bull. Amer. Meteor. Soc., 69, 628-635.

\section{news from our chapters}

\section{Greater Milwaukee}

The 30 January 1991 meeting featured a presentation by Roscoe R. Braham Jr. of the University of Chicago. His topic was "Recent Studies of Lake Effect Snows over Lake Michigan." Braham's slide presentation illustrated some of the major characteristics of this weather phenomenon and highlighted the three classes of organization of convection associated with lake effect snows. He also gave a brief comparison of lake snows in the upper three Great Lakes to how these snow squalls develop in Lakes Erie and Ontario.

Alan Sealls, from WTMJ television in Milwaukee, spoke at the 27 February 1991 meeting on "Broadast Meteorology." He provided us with an enlightening "behind the scenes" look at the effort and equipment involved in putting together local weather forecasts for television and radio broadcasts. Training and career opportunities in the field were also discussed.

\section{Northwest Ohio}

Fourteen members and guests attended the year's first meeting held 30 January 1991 at the National Weather Service Forecast Office, Cleveland, Ohio. Under old business, we discussed participation by chapter members in various scouting activities. Bob Matanick and Richard Vader volunteered to help out as counselors in the merit badge program. The Girl Scout program discussion was deferred to a future meeting. Member Frank Kieltyka is to take care of the
Junior Science Olympiad on 23 February. All required equipment is either in hand or on order in the Kent State University Met/Climate program. Past President Tom Schmidlin was published recently in the AAWO periodical, and President Fred Starheim recently gave a talk about careers in meteorology at Mentor High School.

President Fred Starheim reported on his recent visit to the 71st annual meeting of the AMS.

"Marine Weather Services for the Great Lakes" was the topic presented by our principal speaker for the evening, member Daron Boyce. After a very informative and interesting talk in the conference room, members went to the forecast floor for demonstrations of the newest technology related to the subject.

\section{Southeast Wyoming}

The chapter met for its fifth meeting of the 1990-91 season on 26 February 1991 in Cheyenne, Wyoming. The meeting was held at the National Weather Service Office and was hosted by William T. Parker, MIC, WSFO Cheyenne. Members received a comprehensive tour of the office and an opportunity to view the dissemination of weather service products. A map discussion was held and some meteorology students were given a chance to forecast Cheyenne's weather for a 48-hour period as an exercise in forecasting.

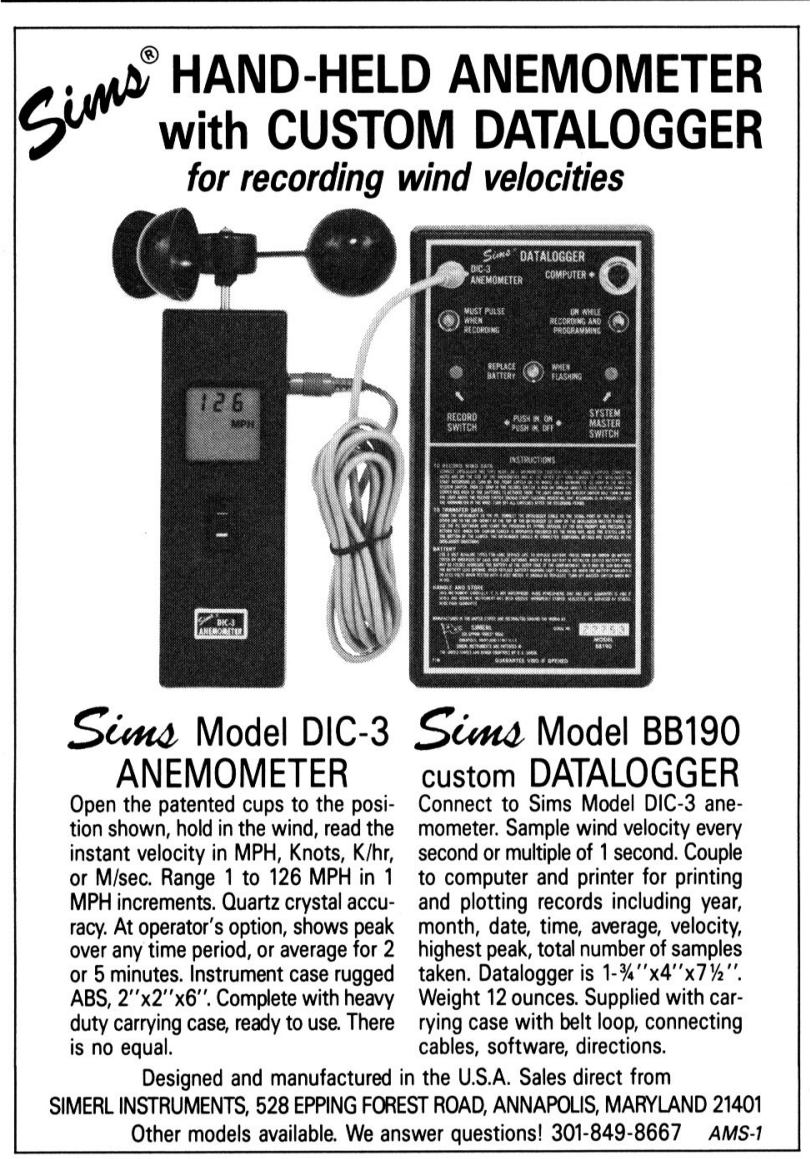




\section{MP-100 METEOROLOGICALPROBE}

FOR ACCURATE MEASUREMENT OF HUMIDITY AND TEMPERATURE

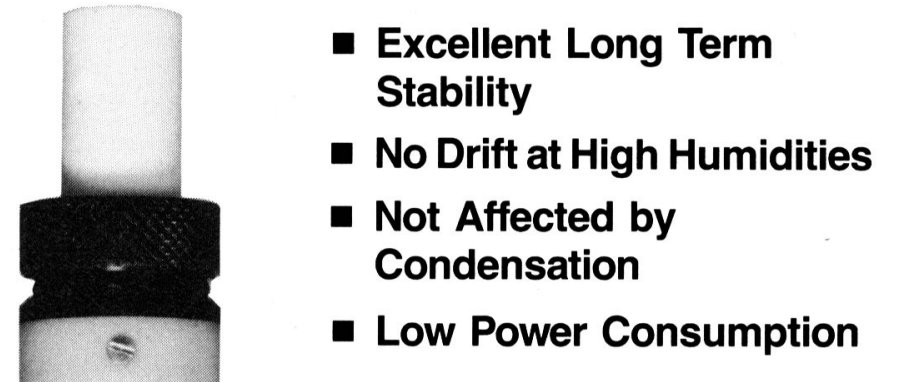

The MP-100 combines the long term stability of the $\mathrm{C}-80$ Hygromer sensor with advanced electronic temperature compensation. This produces a high performance probe for measuring relative humidity in meteorological applications.

With an accuracy ${ }^{*}$ of $\pm 1.5 \% \mathrm{RH}$ or better over a wide temperature range, the MP-100 is meeting the critical data acquisition needs of research scientists. Already proven in the rugged environs of ocean buoys, tropical climates, industrial atmospheres, remote mountain stations and high

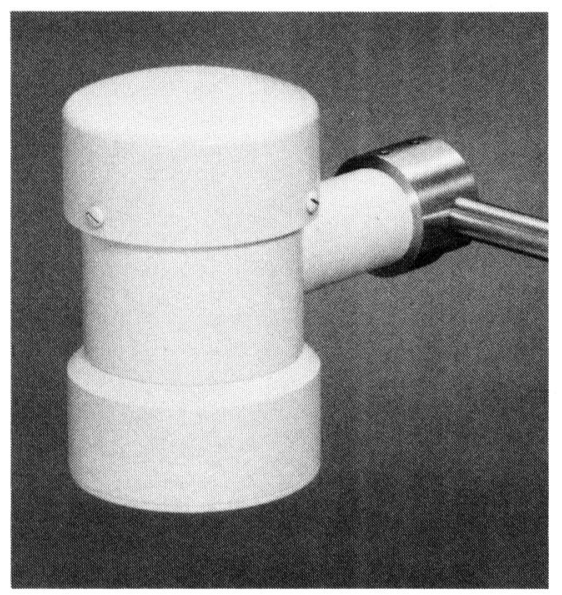

MAS41003

Motor Aspirated Shield

\author{
- High Resistance to \\ Pollutants \\ - Low Maintenance \\ - Type Tested at N.I.S.T. \\ - Type Tested at WMO \\ Intercomparison, Norway
}

pollutant conditions, the MP-100 has given meteorologists a humidity instrument they can depend on.

Rotronic is a leader in $\mathrm{RH}$ measurement because we provide products which meet specifications and perform to the level expected. So, if your requirements demand long term stability, high reliability and essentially zero maintenance, then the MP-100 and Rotronic is the answer.

For more information please call 800-628-7101.

*Tested at N.I.S.T.

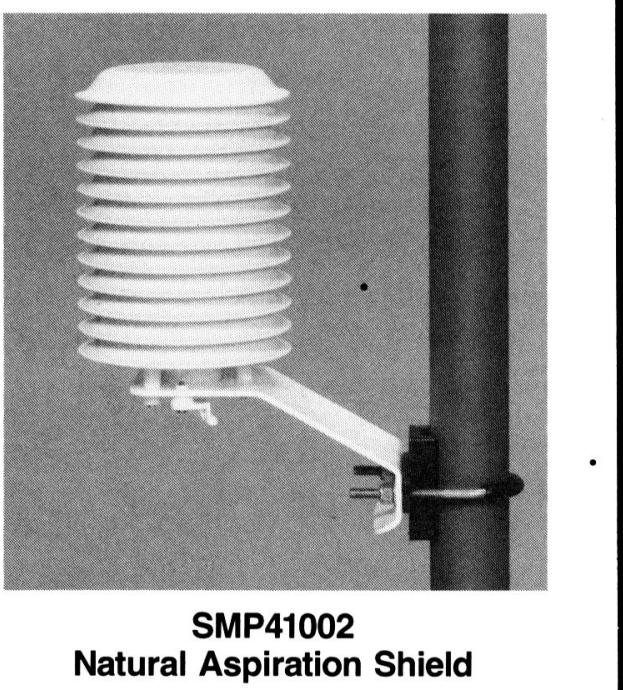

\section{HUMIDITY KNOWLEDGE...THAT WORKS}

160 E. MAIN ST. HUNTINGTON NY 11743 • 516/427-3898 • FAX 516/427-3902 